\title{
VI.6 Development of Advanced Manufacturing Technologies for Low Cost Hydrogen Storage Vessels
}

Mark Leavitt

$\mathrm{P}$ Lam

KM Nelson

BA Johnson

KI Johnson

KJAlvine

Antonio Ruiz

Jesse Adams

October 2012

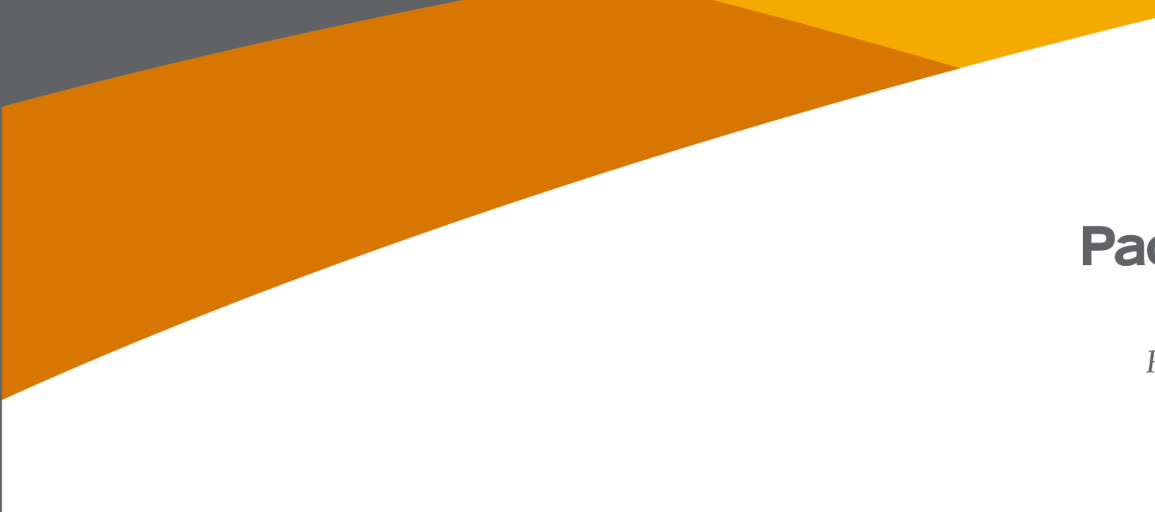


PNNL-21570

\title{
DISCLAIMER
}

This report was prepared as an account of work sponsored by an agency of the United States Government. Neither the United States Government nor any agency thereof, nor Battelle Memorial Institute, nor any of their employees, makes any warranty, express or implied, or assumes any legal liability or responsibility for the accuracy, completeness, or usefulness of any information, apparatus, product, or process disclosed, or represents that its use would not infringe privately owned rights. Reference herein to any specific commercial product, process, or service by trade name, trademark, manufacturer, or otherwise does not necessarily constitute or imply its endorsement, recommendation, or favoring by the United States Government or any agency thereof, or Battelle Memorial Institute. The views and opinions of authors expressed herein do not necessarily state or reflect those of the United States (jovernment or any agency thereof.

\author{
PACIFIC NORTHWEST NATIONAL LABORATORY \\ operated by \\ BATTELLE \\ for the \\ UNITED STATES DEPARTMENT OF ENERGY \\ under Contract DE-AC05-76RL01830
}

Printed in the United States of America
Available to DOF and DOF contractors from the Office of Scientific and Technical Information,
P.O. Box 62, Oak Ridge, TN 37831-0062;
ph: (865) 576-8401
fax: (865) 576-5728
email: reports@adonis.osti.gov

\author{
Available to the public from the National Technical Information Service, \\ U.S. Department of Commerce, 5285 Port Royal Rd., Springfield, VA 22161 \\ ph: (800) 553-6847 \\ fax: $(703) 605-6900$ \\ email: orders@ntis.fedworld.gov \\ online ordering: http://www.ntis.gov/ordering.htm
}




\title{
VI.6 Development of Advanced Manufacturing Technologies for Low Cost Hydrogen Storage Vessels
}

\author{
Mark Leavitt \\ $P$ Lam \\ KM Nelson \\ BA Johnson \\ Kenneth I. Johnson \\ Kyle J. Alvine \\ Antonio Ruiz \\ Jesse Adams
}

October 2012

Prepared for the U.S. Department of Energy under Contract DE-AC05-76RL01830

Pacific Northwest National Laboratory

Richland, Washington 99352 
PNNL-21570 
PNNL-21570

\section{VI.6 Development of Advanced Manufacturing Technologies for Low Cost Hydrogen Storage Vessels}

Mark Leavitt

Quantum Fuel Systems Technologies Worldwide, Inc.

25242 Arctic Ocean Drive

Lake Forest, CA 92630

Phone: (949) 399-4584

E-mail: mleavitt@qtww.com

DOE Technology Development Manager: Antonio Ruiz

Phone: (202) 586-0729; Fax: (202) 586-9811

E-mail: Antonio.Ruiz@ee.doe.gov

DOE Project Officer: Jesse Adams

Phone: (303) 275-4954

E-mail: Jesse.Adams@go.doe.gov

Contract Number: DE-FG36-08GO18055

Subcontractors:

Boeing Research and Technology, Seattle, WA

Pacific Northwest National Laboratory (PNNL), Richland, WA

Project Start Date: $\quad$ September 26, 2008

Project End Date: $\quad$ March 31, 2013

\section{Objective}

Develop new methods for manufacturing Type IV pressure vessels for hydrogen storage with the objective of lowering the overall product cost by:

- optimizing composite usage through combining traditional filament winding (FW) and advanced fiber placement (AFP) techniques,

- exploring the usage of lower-strength, higher-modulus fibers on the outer layers of FW,

- building economic and analytical models capable of evaluating FW and AFP processes including manufacturing process variables and their impact on vessel mass savings, material cost savings, processing time, manufacturing energy consumption, labor and structural benefits, and

- studying polymer material degradation under high-pressure hydrogen environment to optimize storage volume.

\section{Technical Barriers}

The project addresses the following technical barriers from the Manufacturing R\&D section (3.5) of the Hydrogen, Fuel Cells \& Infrastructure Technologies Program Multi-Year Research, Development and Demonstration Plan:

(G) High-Cost Carbon Fiber

(H) Lack of Carbon Fiber Fabrication Techniques for Storage Tanks

\section{Contribution to Achievement of DOE Manufacturing R\&D Milestones}


This project will contribute to achievement of the following DOE milestone from the Manufacturing R\&D section of the Hydrogen, Fuel Cells \& Infrastructure Technologies Program Multi-Year Research, Development and Demonstration Plan:

- Milestone 6.2: Develop fabrication and assembly processes for high pressure hydrogen storage technologies that can achieve a cost of $\$ 6 / \mathrm{kWh}$. $(4 \mathrm{Q}, 2015)$

\section{Accomplishments}

- Modified the current in-house computer program (KWind) for generating a finite element analysis (FEA) model of the composite shell using the filament winding process to mWind, which allows more composite shell layer options using AFP methods.

- Completed the next vessel design with mWind to incorporate lower-cost fiber in addition to AFP dome caps and baseline fiber.

- Implemented infrared (IR) heater to reduce cutter jamming and improve precision of heated area for manufacturing AFP dome caps.

- Re-engineered the tensioning system, which utilizes low-cost active control (passive feedback controls) allowing consistent tension, and avoids slack during head and arm movements.

- Conducted process improvements to reduce marcelling or wrinkling in AFP end dome plies.

- Built and tested an in-situ tensile rig for high-pressure hydrogen to test polymer materials.

\section{Introduction}

The goal of this project is to develop an innovative manufacturing process for Type IV high-pressure hydrogen storage vessels, with the intent to significantly lower manufacturing costs. Part of the development is to integrate the features of high precision AFP and commercial FW. Evaluation of an alternative fiber to replace a portion of the baseline fiber will help to reduce costs further.

\section{Approach}

The hybrid vessel designs were based on FEA results to optimize strain distribution and achieve uniform displacement in the domes of the vessel. The in-house software for generating a FEA model of the composite shell based on the filament winding process was modified to allow more composite shell layer options using the AFP methods. AFP dome caps were manufactured by Boeing according to FEA results. A series of testing to national standards will be conducted to validate the hybrid designs.

\section{Results}

Vessel Designs

Vessel 8: In the 2011 annual report, it was reported that Vessel 8, which was an identical build to Vessel 7 (passed burst test at 22,925 psi; requirement is $22,843 \mathrm{psi}$ ), did not pass the ambient cycle test at Quantum. It completed 13,500 out of the required 15,000 cycles.

After cutting the forward dome off the vessel, it was found that the liner was bonded to the composite at two different locations. One was near the forward boss, and the other was along the entire circumference of the transition area between AFP and FW on the forward dome. The bonding was caused by curing the vessel at a temperature that was too close to the softening temperature of the liner material. On the vessels for ambient cycle tests in the future, a plastic film with higher melting temperature than the desired curing temperature will be applied between the liner and composite to prevent bonding. Previous experience with this film assures that this failure mode will not repeat in the future.

Vessel 9: With the failure mode of Vessel 8 understood, Vessel 9 was designed to utilize lower-cost fiber to further reduce vessel cost. The identified lower-cost fiber has lower strength but higher modulus than the baseline fiber. The rationale is that the outer layers experience a lesser load than the inner layers; 
therefore, usage of baseline fiber on the outside is not necessary. Meanwhile, the higher modulus property distributes the load onto the outer layers without overloading the inner baseline fiber layers.

To satisfy the design criteria established by Vessel 7 in the FEA, two additional helical patterns were added to maintain the same strains. Overall $37 \%$ of the baseline fiber in Vessel 7 was replaced with lower-cost fiber in Vessel 9. Although an additional fiber type was introduced in the design, the resin system remained the same for the entire FW process. The cost savings and weight increase are detailed out in the Cost Model section of this report.

The result was 5.2 MPa (760 psi) short of the burst requirement. The failure location was at the tangent between the cylinder section and the aft dome. Since the result was very close to the requirement and the vessel was wound over two days (due to winding pattern development), it was determined to repeat the Vessel 9 build. Experience shows a 10\% performance gain when a vessel is wound in just one day.

Vessel 10: Vessel 10 only improved by $2.1 \mathrm{MPa}(305 \mathrm{psi}$ ) from Vessel 9 in burst pressure. The improvement was negligible. The failure location was again at the tangent between the cylinder section and the aft dome. The result indicated that it was not a manufacturing issue of winding over two days.

Vessel 11: The allowable strains of Vessels 9 and 10 were based on the successful results of Vessel 7, which passed the burst test by $0.56 \mathrm{MPa}(82 \mathrm{psi})$. Both Vessels 9 and 10 results showed that the design criteria used in the previous analyses were too aggressive to ensure successful burst tests. Therefore, all but seven of the lower-cost fiber layers were replaced back with the baseline fiber. Although this design would make the vessel heavier and more expensive than Vessel 7, it would verify whether the failure was caused by using the wrong fiber material properties or other design issues.

Surprisingly the burst test result was lower in Vessel 11 than those of Vessels 9 and 10. It only achieved 138.1 MPa (20,026 psi), although the allowable fiber strains from analysis were even lower than those of Vessel 7. This vessel also failed at the tangent between the cylinder section and the aft end. While the vessel was designed with the highest strain in the cylinder section, the burst location was at the tangent. It shows the analysis method needs to be modified to accommodate the hybrid (AFP + FW) design.

\section{FEA Model Generation Software Upgrade}

The current in-house computer program (KWind) generates a FEA model of the composite shell using the filament winding process. KWind was originally written for only filament wound pressure vessels and was rewritten (called mWind) to allow more composite shell layer options using AFP methods.

KWind only models the ending points of a composite layer created during filament winding, but it does not allow a composite layer to have a starting point which can be generated using the AFP process. Up to this point in time, models generated with KWind were hand modified to account for different start and stop points in the middle of a layer. These modifications left unused elements in the layers that did not model the composite structure correctly. The overlap areas where plies started and stopped in the middle of the layer were also not modeled correctly to provide accurate results.

The basic methodology of KWind was to build the composite shell one layer at a time. mWind took the approach of taking a small section of the composite shell and building up each layer in the section. This allows the model to add and subtract layers through the model with start and stop points for each layer. mWind starts by building a base model from the geometry, material properties and composite layup information. The base model and loading conditions are used to write an input file for a 2D axisymmetric 
shell model, a 3D shell model, or the traditional 2D axisymmetric continuum model similar to KWind. Currently mWind writes shell models to the FEA program ABAQUS.

KWind contains a subroutine to read the results of finite element solution and calculate fiber strains for selected layers in the composite structure. mWind also has incorporated this subroutine to calculate and plot fiber strains. For plotting, the graphics calls of KWind were not translated. Instead the graphics functions of Excel are used. mWind also reads the base finite element results into Excel and allows users to create other calculations and plots using Excel commands and other user written subroutines. mWind also has subroutines to read and store analysis results into an Excel worksheet without the base model information. This latest software was used to design Vessel 12 to incorporate AFP with baseline and lower-cost fibers. The built was just completed at the time of writing this report.

\section{New Six-Tow Quarter-Inch Head Integration (AFP)}

Boeing has built and implemented the next-generation fiber placement head, specifically designed for the fiber placement of pressure vessels. Laying towpreg (resin-impregnated tow) on the vessel or liner demands a very narrow head that can pass as close to the polar bosses as possible to allow many design options for optimal vessel performance. The new fiber placement head assembly has been integrated into Boeing's AFP KUKA KR240 long arm robotic cell. The integration also includes the kinematic linking between the robot and the head stock (rotation axis) to which the dome tool is fixed. This allows the translation and rotation between the motions of the robot and the tool to be linked to one another. Tests were conducted to verify that no slipping or misalignment was present in the layup that would be caused by the kinematics between the robot and the head stock.

\section{Advanced Tensioning System}

Boeing has also incorporated a new dynamic spool tension system, capable of accurately controlling the tension of each spool as material is both pulled off and rewound back onto the spool. The underlying goal of a tensioning system is a low-cost, highly-reliable system that can be packaged on the arm of a mediumsized robot without overloading its payload capacity. The advanced design improves upon reducing slack in the system when tow is needed to be "taken up" or back spooled, as well as creating a consistent desired level of tension throughout the entire layup process. This is created by adding dancer arms to pick up the excess slack in the system caused by the response rate of the motor as it changes both direction and torque/velocity levels. The new tensioning system reduces the amount of high-level tension seen during the starts and directional change, giving it a more consistent level of tension throughout the course layup. A closed-loop, feed-back control system reduces the excessive spike levels of tension in the system during layup, increasing the overall quality of the layup.

Newly Designed Infrared Heating System

At Boeing, a newly designed infrared heating system was incorporated into the head to overcome limitations with the previous hot-gas heater. Previous issues included hot gas pockets, hot air entering cutter region, frequent cutter jams associated with excessive heating, unable to control heated area efficiently, and noise level. Figure 1 shows the IR heating system in use on our first Phase III forward dome cap. The new heating system has increased the reliability and productivity by eliminating excessive heating of the cutter blade. The heated zone of the IR heating system is better controlled, allowing for a more efficient and effective system.

\section{Cost Model}

The estimated cost of Vessel 9 was compared with Vessel 7 by PNNL. A cost savings of more than 5\% was estimated (based on low volume price of $\$ 13 / \mathrm{lb}$ for low-cost fiber vs. the $\$ 16 / \mathrm{lb}$ for baseline fiber) with a weight increase of less than $2 \%$. During the year, the cost models were also used to provide 
information on the possible cost savings of advanced vessel manufacturing methods to the National Academies of Science (NAS) review of the U.S. DRIVE (former Freedom Car) program.

\title{
Polymer Materials Characterization
}

At PNNL, the in-situ tensile test frame (Figure 2) was further refined and used to quantify the effects of high-pressure hydrogen on polymer vessel liner materials. The miniature tensile frame $(28 \mathrm{~cm}$ in height, $12 \mathrm{~cm}$ in diameter) fits inside the high-pressure autoclave and is actuated by a solenoid. HDPE samples were pulled in air and in 100\% hydrogen at 4,000 psi hydrogen. Figure 3 shows that hydrogen in the polymer structure (the blue curve) lowers both the elastic modulus and the yield strength. Additional tests of different HDPE materials are being analyzed for documentation in the final technical report and a peerreviewed publication. While the test frame has been used exclusively for polymer testing to date, metal foils could also be tested if the sample cross-sectional area was matched to the maximum load of the system. The system has been shown to work reliably in pure hydrogen.

\section{Conclusions and Future Directions}

- Test results in 2011 showed that this hybrid process is a promising method to reduce vessel cost. $22.9 \%$ of composite was saved while equipment and factory costs for the process are small relative to the composite savings.

- In-house software has been modified to generate more accurate FEA models of the composite shell specifically for AFP.

- Lower-cost fiber has been incorporated with baseline fiber and AFP to further reduce vessel cost by $5 \%$ while keeping weight increase to less than $2 \%$.

- AFP manufacturing tooling and method have been improved to deliver higher quality dome caps.

- Boeing is working on the next revision of the tension controls, further refining the tensioning, allowing faster response in directional change, and enabling active feedback controls.

- For further understanding of polymer material behaviors in high-pressure hydrogen, PNNL has built and tested an in-situ tensile rig that operates at 4,000 psi.

- Perform burst test, ambient temperature cycle test, extreme temperature cycle test and accelerated stress rupture test to validate process and material changes critical to the hybrid vessel design.

- Update cost model with the cost and amount of lower-cost fiber used in the final hybrid design.

- Complete in-situ testing of HDPE in hydrogen at pressure.

\section{FY 2012 Publications/Presentations}

1. Development of Advanced Manufacturing Technologies for Low Cost Hydrogen Storage Vessels, Annual Merit Review, Department of Energy, May 14-18, 2012, Washington, D.C.

2. Development of Advanced Manufacturing Technologies for Low Cost Hydrogen Storage Vessels, Hydrogen Storage Tech Team, June 21, 2012, Oak Ridge National Lab, Oak Ridge, Tennessee

\author{
Acronyms \\ AFP Advanced fiber placement \\ FW Filament winding \\ FEA Finite element analysis \\ IR Infrared \\ HDPE High density poly-ethylene \\ LVDT Linear variable differential transformer
}

\section{Figure Captions}


PNNL-21570

Figure 1. Implemented New Infrared Heating System, which Reduces the Frequency of Cutter Jams due to Excessive Heating in the Cutter Region.

Figure 2. Side View of the In-situ Tensile Tester showing the (1) Load Cell, (2) Sample Grips, (3) LVDT, (4) Solenoid, and (5) Support Frame.

Figure 3. Difference in Modulus between the HDPE Pulled in Air (Blue) and the HDPE Pulled in HighPressure Hydrogen (Red). 
PNNL-21570

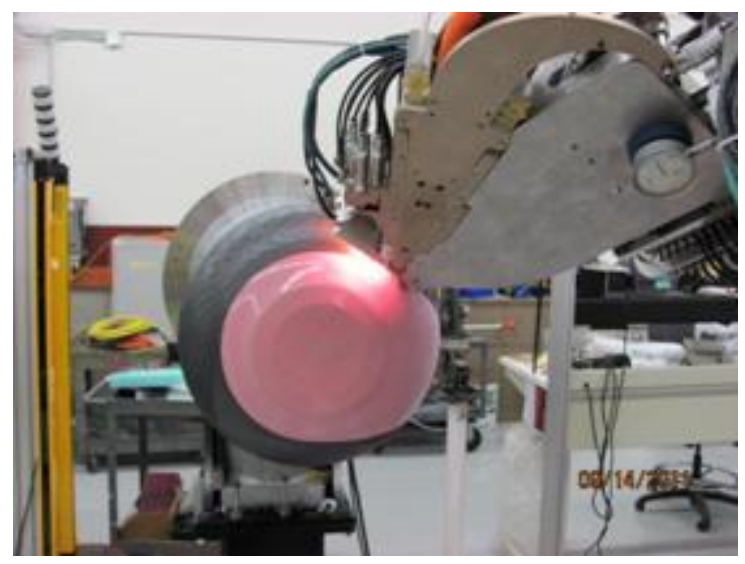

Figure 1 
PNNL-21570

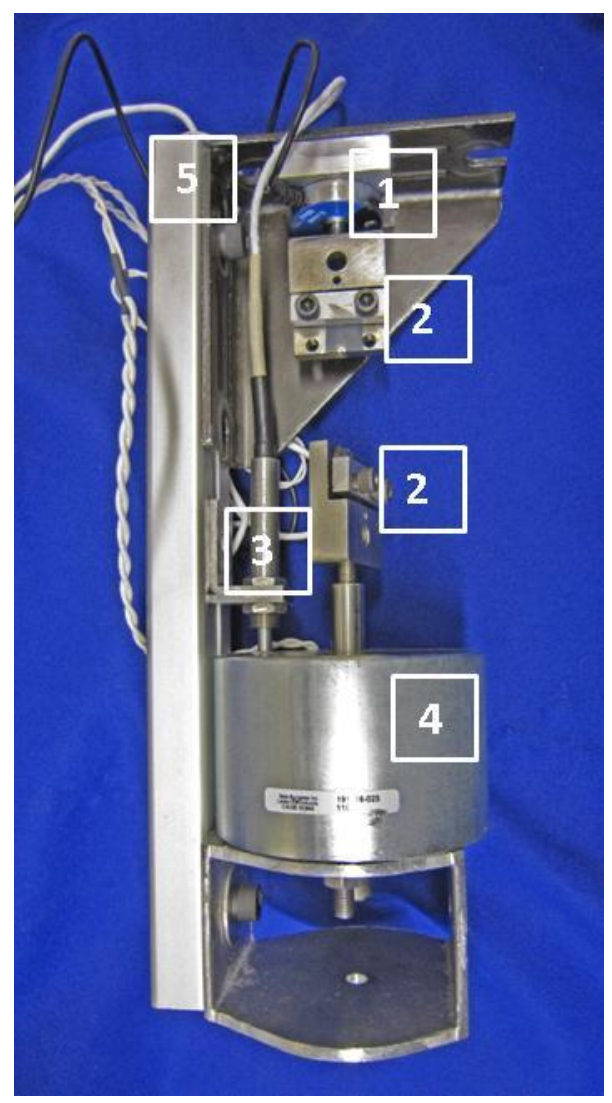

Figure 2 
PNNL-21570

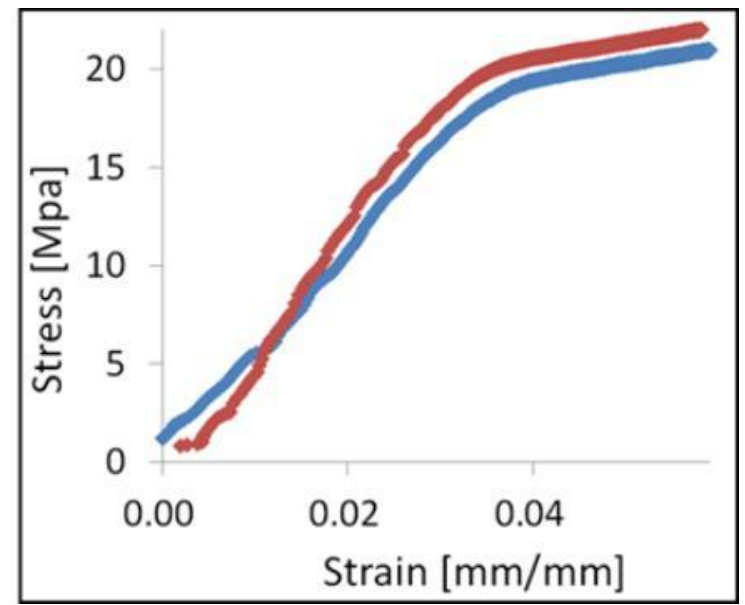

Figure 3 